\title{
Hepatic Differentiation of Murine Disease-Specific Induced Pluripotent Stem Cells Allows Disease Modelling In Vitro
}

\author{
Reto Eggenschwiler, ${ }^{1}$ Komal Loya, ${ }^{1}$ Malte Sgodda, ${ }^{1}$ Francoise André, ${ }^{1}$ and Tobias Cantz ${ }^{1,2}$ \\ ${ }^{1}$ Stem Cell Biology, Cluster of Excellence REBIRTH, Hannover Medical School, 30625 Hannover, Germany \\ ${ }^{2}$ Max Planck Institute for Molecular Biomedicine, 48149 Münster, Germany \\ Correspondence should be addressed to Tobias Cantz, t.cantz@mpi-muenster.mpg.de
}

Received 17 March 2011; Revised 12 July 2011; Accepted 13 July 2011

Academic Editor: Shinn-Chih Wu

Copyright ( 2011 Reto Eggenschwiler et al. This is an open access article distributed under the Creative Commons Attribution License, which permits unrestricted use, distribution, and reproduction in any medium, provided the original work is properly cited.

\begin{abstract}
Direct reprogramming of somatic cells into pluripotent cells by retrovirus-mediated expression of OCT4, SOX2, KLF4, and CMYC is a promising approach to derive disease-specific induced pluripotent stem cells (iPSCs). In this study, we focused on three murine models for metabolic liver disorders: the copper storage disorder Wilson's disease (toxic-milk mice), tyrosinemia type 1 (fumarylacetoacetate-hydrolase deficiency, $\mathrm{FAH}^{-/-}$mice), and alpha1-antitrypsin deficiency (PiZ mice). Colonies of iPSCs emerged 2-3 weeks after transduction of fibroblasts, prepared from each mouse strain, and were maintained as individual iPSC lines. RT-PCR and immunofluorescence analyses demonstrated the expression of endogenous pluripotency markers. Hepatic precursor cells could be derived from these disease-specific iPSCs applying an in vitro differentiation protocol and could be visualized after transduction of a lentiviral albumin-GFP reporter construct. Functional characterization of these cells allowed the recapitulation of the disease phenotype for further studies of underlying molecular mechanisms of the respective disease.
\end{abstract}

\section{Introduction}

To date, more than 200 liver-based defects are identified, which can cause hepatic and extrahepatic diseases, and such inborn errors of liver metabolism account for $15 \%$ to $20 \%$ of liver transplantation indications for children. Hence, the elucidation of the molecular pathways of liver regeneration and extensive preclinical cell transplantation experiments in animals have led to the application of hepatocyte transplantation in a number of patients with hereditary metabolic liver disease and acute liver failure [14]. In these first clinical studies, hepatocyte transplantation has been considered either as a full-treatment option, or, in more severe situations as a bridge to transplantation [5]. Furthermore, it was shown that cryopreserved hepatic cells from one organ could be applied for multiple children [6].

The generation of iPS cells from adult somatic cells by retrovirus-mediated expression of pluripotency-associated genes in mice [7-10] and in humans [11-13] offers a unique tool to generate disease-specific iPS cells for pathophysiological studies (Figure 1). As a proof-of-principle, it was demonstrated in recent publications that iPS cells from a murine sickle cell anaemia model as well as from Fanconi Anaemia patients can be generated, repaired, and used for the correction of the disease by transplantation $[14,15]$. However, in order to use those iPS derivatives for studies of the disease, suitable differentiation protocols need to be applied to get a disease-specific cell phenotype. In the past, we and others have generated hepatic precursor cells from human and mouse embryonic stem-cell lines [16-19]. With the existing differentiation protocols, a primitive hepatic phenotype with foetal gene expression patterns can be induced in the majority of the embryonic stem cells $[16,20]$. Transplantation of these cells, however, have so far resulted only in scattered formation of hepatocytes or were reported to form small hepatocyte clusters in major urinary protein promoter- (Mup-) driven urokinase-type plasminogen activator (uPA) and $\mathrm{FAH}^{-/-}$mice [21-23]. Nevertheless, hepatic cells suitable for pharmacological testing have been described [24], and in a more recent publication, hepatic cell differentiation of human ES cells was refined [25] achieving 


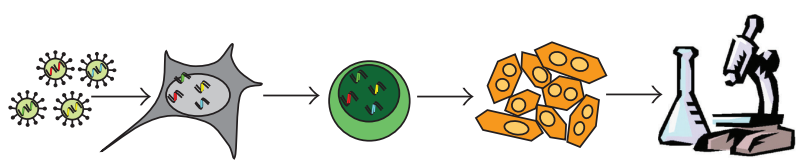

Figure 1: iPS cells as model to study metabolic liver diseases. Induced pluripotent stem cells (iPSCs) can be generated using retro- or lentiviral constructs expressing the canonical reprogramming factors Oct4, Klf4, and Sox 2 with or without c-Myc. This technique allows the generation of pluripotent stem cells from diseased individuals. Subjection of these iPS cells to hepatic differentiation protocols results in an easily accessible source of disease-specific hepatic cells. Importantly, this technique might pave the way for in depth study of corresponding liver diseases.

transplantable hepatic cells, which functionally engrafted in livers of immunodeficient mice.

In our studies, we aimed on generating disease-specific iPS cell from mice carrying genetic defects for three clinically relevant metabolic liver diseases. As murine model of the copper storage disorder Wilson's disease, we chose the socalled toxic milk mice, which carry a point mutation in the ATP7b gene [26] and closely represent the disease phenotype in patients [27]. As model for acute tyrosinemia type I, we studied fumarylacetoacetate hydrolase-deficient $\left(\mathrm{FAH}^{-} /^{-}\right)$ mice [28], which also serve as a well established liver regeneration model for studies on hepatic cell transplantation mechanisms. Finally, we investigated a transgenic mouse strain, which expresses the mutated isoform of the human $\alpha 1$-antitrypsin variant (PIZ) and which depicts liver damage related to accumulation of the misfolded proteins [29].

\section{Materials and Methods}

2.1. Mice, Animal Tissue Samples, and Cell Sources. $\mathrm{C} 3 \mathrm{HeB} / \mathrm{FeJ}-\mathrm{Atp} 7 \mathrm{btx}-\mathrm{J} / \mathrm{J}$ (common name: toxic-milk mice) were obtained from Jackson Lab (Bar Harbor, Me, USA). $\mathrm{FAH}^{-/-}$-mice were provided by Arndt Vogel (Hannover Medical School, Germany), and tissue samples (ear cuts and tail tips) from adult PiZ mice were obtained from Robert Bals (University of Homburg/Saar, Germany). All animals were maintained and handled in accordance with institutional guidelines with free access to food and water. Murine embryonic stem cells carrying an Oct4 promoterdriven eGFP transgene derived from OG2 mice [30] as well as embryonic stem cells derived from $\mathrm{C} 3 \mathrm{H}$ mice (Charles River) were provided by the Max Planck Institute for Molecular Biomedicine (Münster, Germany).

2.2. Isolation and Reprogramming of Adult Mouse Fibroblasts. Fibroblasts were isolated foetuses of toxic-milk and $\mathrm{FAH}^{-/-}$ mice (ED 13.5) and ear cuts of adult PiZ mice, respectively. Cells were maintained in DMEM low glucose (PAA, Austria) supplied with 10\% FBS (PAA), 1\% Penicillin/Streptomycin + L-Glutamine (PAA) and $100 \mu \mathrm{M} \beta$-Mercaptoethanol (Gibco, Germany). One day before transduction, fibroblasts were seeded at 100,000 cells per well of a 6-well plate (TPP, Switzerland). Next day, toxic-milk and $\mathrm{FAH}^{-/-}$fibroblasts were transduced with $3 \mu \mathrm{L}$ each of concentrated retroviral reprogramming vectors hOCT4, hSOX2, hKLF4, and hCMYC, whereas PiZ fibroblasts were transduced with $3 \mu \mathrm{L}$ each of concentrated lentviral hOCT4, hSOX2, and hKLF4. Cells were cultured for 24 days in mouse ES cell medium supplemented with leukemia inhibitory factor (LIF) and replated on a $6 \mathrm{~cm}$ dish of $\mathrm{C} 3 \mathrm{H}$ mouse embryonic fibroblast (MEF) feeder cells. 6 days later, colonies were picked and subcloned.

\subsection{Production of Lentiviral and Gamma-Retroviral Vectors.} For lentiviral vectors production, one day before transfection, HEK $293 \mathrm{~T}$ cells were seeded at $3 \times 10^{6}$ cells per $10 \mathrm{~cm}$ dish (TPP) in DMEM complete (DMEM high glucose, PAA) supplied with $10 \%$ FBS (PAA) and $1 \%$ Penicillin/Streptomycin + L-Glutamine (PAA). On the day of transfection, medium was exchanged with $8 \mathrm{~mL}$ DMEM complete supplemented with $25 \mu \mathrm{M}$ Chloroquine (SigmaAldrich, Germany). Plasmids encoding for lentiviral gag/pol (pCDNA3.GP.CCCC, $10 \mu \mathrm{g}$ ), RSV-Rev (pRSV-Rev, $5 \mu \mathrm{g}$ ), VSV-G (pMD2.G, $2 \mu \mathrm{g}$ ), and packaging plasmid encoding for respective transgene (SFFV-hOCT4, SFFV-hSOX2, SFFVhKLF4, SFFV-hC-MYC, and Alb-GFP, $10 \mu \mathrm{g}$ ) were mixed in $400 \mu \mathrm{L}$ of $\mathrm{ddH}_{2} \mathrm{O}$ and $100 \mu \mathrm{L}$ of $1.25 \mathrm{M} \mathrm{CaCl}_{2}$. The plasmids- $\mathrm{CaCl}_{2}$ mixture was added dropwise to $2 \mathrm{xHBS}$ and observed until precipitates became visible in phase-contrast microscope and then added to HEK cells. 7 hours later, medium was exchanged with $10 \mathrm{~mL}$ DMEM complete, and 36 hours later, supernatant was collected, passed through $0.45 \mu \mathrm{m}$ filter, and centrifuged at $14,000 \times \mathrm{g}$ for $8 \mathrm{~h}$. Virus pellet was resuspended in PBS (PAA) in $0.5 \%$ of volume of collected supernatant (200-fold concentration). Gammaretroviral vectors were produced as previously reported [31].

2.4. Pluripotent Stem-Cell Culture. Murine iPSC and OG2 (Oct4-GFP transgenic) embryonic stem (ES) cells were cultivated on mouse embryonic fibroblasts on gelatinized dishes (Falcon BD) in culture medium I (Knock Out DMEM, Invitrogen) supplemented with 15\% FCS (selected batches) and additives: $0.2 \% 50 \mathrm{mM} \beta$-Mercaptoethanol, $1 \%$ Pen/Strep/L-Gln, 1\% nonessential amino acids (all PAA) and $10 \mathrm{ng} / \mathrm{mL}$ recombinant human leukemia inhibitory factor (LIF, Chemicon).

2.5. Immunocytochemistry. Cells were seeded on $\mathrm{C} 3 \mathrm{H}$ feeder cells three days prior to cytochemistry staining at a density of 50 cells per well in a 24-well dish (TPP). Cells were fixed with $4 \%$ PFA for $20 \mathrm{~min}$ at $4^{\circ} \mathrm{C}$, washed twice with TBS, and permeabilized with $0.1 \%$ Tween 20 and $0.05 \%$ NP-40 in TBS for $30 \mathrm{~min}$ at room temperature (RT). Fixed cells were blocked with 5\% BSA in TBS for $30 \mathrm{~min}$ at RT, and washed three times with TBS. Primary antibody was diluted in TBS 1:75 for Nanog (Santa Cruz, sc-30328) and 1:100 for Oct4 (Santa Cruz, sc-5279), incubated for $1 \mathrm{~h}$ at RT and washed three times. Secondary antibody was diluted $1: 400$ in TBS (Invitrogen: Nanog Alexa Fluor 647A21447 and for Oct4 Alexa Fluor 488 A11001) and incubated for $45 \mathrm{~min}$ at RT. Cells were washed twice and stained with $0.2 \mu \mathrm{g} / \mathrm{mL}$ DAPI (Invitrogen D3571) in TBS for $1 \mathrm{~min}$ at RT. Cells were 
washed twice and analysed using Olympus IX71 and Cell P software.

2.6. Alkaline Phosphatase (AP) Staining. AP staining was performed using the Chemicon Alkaline Phosphatase Detection Kit (Millipore, USA) according to manufacturer's protocol.

2.7. cDNA Synthesis and Taqman-Based qRT PCR. cDNA synthesis was performed using the SuperScriptTM III FirstStrand Synthesis System for RT-PCR Kit (Invitrogen, USA) with Random Hexamers. Taqman-based qRT PCR assays were performed on the StepOne Plus Cycler (Applied Biosystems) using the standard settings. Taqman probes were ordered from Applied Biosystems for murine $\beta$ Actin (Mm00607939_s1), Oct4 (Mm00658129_gH), Sox2 (Mm00488369_s1), Nanog (Mm02019550_s1), Albumin (Mm00802090_m1), Afp (Mm00431715_m1), Ck18 (Mm01601706_g1), Abcc2 (Mm00496899_m1), Ttr (Mm00443267_m1), Hnf4a (Mm00433964_m1) and human SERPINA1 (Hs01097800_m1), OCT4 (Hs_03005111_g1), SOX2 (Hs_01053749_s1), KLF4 (Hs_00358836_m1), and C-MYC (Hs_01570247_m1). Analyses of exogenous retrovirally expressed murine reprogramming was performed using the following primer/probe combinations: pMXs-Oct4 for:TGGTACGGGAAATCACAAGTTTG, rev:GTCATAGTTC CTGT TGGTGA AGTTCA, probe:6FAM-CTTCACCATGCCCCTCA-MGB; pMXsSox2 for: G T G T G G T G G T A C G G GA A A T C A C, rev: TTCAGCTCCGT CTCC ATCATG, probe:6FAM TGTACAAAAAAGCAGGCTTGT-MGB; pMXs-Klf4 for: GTGTGGTGGTACGGGAAATCA, rev: CGCGAACGTGG AGAA GGA, probe: 6FAM-CTTCACCATGGCTGTCAGMGB; pMXs-cMyc for: TGGTACGGGAAATCACAAGTTTG, rev: GTCATAGTTCCTGTTGGTGAAGTTCA, probe: 6FAM-CTTCACCATGCCCCTCA-MGB.

2.8. Teratoma Assays. For teratoma formation assays, $1 \times 10^{6}$ cells were transplanted subcutaneously into NOD/SCID mice and grown for 2-3 months. Mice were sacrificed, and teratomas were fixed in 10\% formalin and embedded into paraffin. Sections were stained with Hematoxylin and Eosin and evaluated for the formation of the three germ layers.

2.9. Hepatic Differentiation Protocol. iPSCs were differentiated with a modified version of the hanging drop method as previously published by Kania et al. [17]. Briefly, iPSCs were trypsinized and preplated on gelatin-coated $6 \mathrm{~cm}$ dishes (TPP) for $45 \mathrm{~min}$ for separation from feeder-cells. iPS cell containing supernatants were centrifuged at $250 \times \mathrm{g}$ for $4 \mathrm{~min}$ and resuspended in mouse ES cell culture medium without LIF to 30000 cells $/ \mathrm{mL}$. From this cell suspension, $50 \times 20 \mu \mathrm{L}$ hanging drops were put on the inside of the lid of a $10 \mathrm{~cm}$ dish and grown at $37^{\circ} \mathrm{C}$ in $5 \% \mathrm{CO}_{2}$ incubator for embryoid body (EB) formation. At day 5, EBs were collected and kept in IMDM with $20 \%$ FBS, $1 \%$ Pen/Strep/L-Gl n, $1 \%$ nonessential amino acids, $0.2 \% 50 \mathrm{mM} \beta$-Mercaptoethanol, $0.1 \% 450 \mathrm{mM} \alpha$-Monothioglycerol (all PAA) on gelatincoated 6-wells (25 EB's per well). 9 days later, cells were trypsinized and transferred on rat tail collagen type I(Roche Diagnostics) coated 6-wells and kept in IMDM for overnight attachment. Next day, cells were washed once with PBS and kept on HCM with SingleQuots (Lonza) for further hepatic differentiation for 14-20 days. In case of transduction with lentiviral Alb-GFP reporter construct, $1 \times 10 \mathrm{e} 6$ lentiviral particles (MOI $\sim 3-5)$ were added to $2 \mathrm{~mL} \mathrm{HCM}$ in each well of a 6 -well at day $5+9+3$ and incubated for $48 \mathrm{~h}$ before medium exchange. This protocol yields in transduction efficacy close to $100 \%$ in murine hepatoma cells (Hepa 1-6) with on negligible expression in nonhepatic cells, such as fibroblasts. Hepatic differentiation efficiency was estimated by FACS analysis for GFP-positive cells at the end of differentiation on a BD FACS Calibur (BD Biosciences).

2.10. Albumin ELISA. Cell supernatant was harvested after three days from day $5+9+14$ hepatic differentiated cells. Supernatant of Hepa 1-6 cells served as a positive control and was diluted $1: 1$ with fresh media. The ELISA was performed according to manufactures protocol (Mouse albumin ELISA Kit; Bethyl Laboratories) using $100 \mu \mathrm{L}$ supernatant per reaction. The primary antibody was diluted $1: 1,000$, the secondary antibody $1: 10,000$ and TMB ELISA Substrate was added (Thermo Scientific Pierce, USA). Secreted albumin was calculated per 1,000 cells and normalized to time.

2.11. Urea Production. Urea production was analysed using the diacetyl monoxime method [32]. Supernatant was harvested after three days from day $5+9+14$ hepatic differentiated cells. For the colour reaction, $100 \mu \mathrm{L}$ supernatant was mixed with $1400 \mu \mathrm{L}$ reagent (distilled water, mixed acid reagent, and mixed colour reagent in the ratio $1: 1: 1$ ) and boiled for $15 \mathrm{~min}$ at $98^{\circ} \mathrm{C}$. Absorbance was detected using a $540 \mathrm{~nm}$ filter in a single point measurement. The results were normalized 10,000 cells and $24 \mathrm{~h}$.

2.12. Cytochrome P450 Activity. Activation of cytochrome P450 subtype $1 \mathrm{~A} 1$ was determined using the EROD assay [33]. Fresh media containing $10 \mu \mathrm{M}$ dicumarol and $8 \mu \mathrm{M} 7$ ethoxyresorufin was added for two hours on day $5+9+$ 14 hepatic differentiated cells. $75 \mu \mathrm{L}$ of cell supernatant was mixed with $25 \mu \mathrm{L} 0.1 \mathrm{M} \mathrm{Na}$-Ac solution and incubated with 10 units of $\beta$-glucuronidase/arylsulfatase for $2 \mathrm{~h}$ at $39^{\circ} \mathrm{C}$. Reaction was stopped by adding $200 \mu \mathrm{L}$ EtOH, and resorfurin was analysed photometrically using $535 \mathrm{~nm}$ excitation and $595 \mathrm{~nm}$ emission filters. Results were normalized to 10,000 cells and $2 \mathrm{~h}$.

2.13. Karyotype Analysis. Cells were treated with $10 \mu \mathrm{m} / \mathrm{mL}$ Nocodazole for 8 hours to arrest cells in metaphase. These cells were then collected after trypsinization and lysed in $0.56 \% \mathrm{KCl}$ before fixation in methanol: acetic acid $(3: 1)$. The cell nuclei were then dropped on glass slides from a height of 1.5 meters and further stained with DAPI for chromosomal count analysis. 


\section{Results and Discussion}

3.1. iPSC from the Murine Model of Wilson's Disease. As first murine model of hepatic liver diseases, from which we generated iPSCs, we chose Jackson toxic-milk mice. These mice reflect the human disorder Wilson's disease leading to fibrotic changes, inflammatory infiltration, and copper accumulation in the mice's liver [27]. Toxic-milk mice-derived iPSCs were generated using foetal fibroblasts cultured under adherent monolayer conditions. Cells were transduced with gamma-retroviruses encoding for the mouse Oct4, Sox2, Klf4, and c-Myc cDNAs [7, 31] and maintained under normal feeder cell culture conditions. After six days, the transduced cells were split and seeded on irradiated feeder cells applying standard mouse embryonic stem-cell culture conditions. About two weeks later colonies with different morphologies emerged from the initially transduced cells (Figure 2(a)). Those colonies, which morphologically most closely resembled normal embryonic stem cells, were mechanically picked and subcloned, prior to further cultivation for derivation of individual iPSC lines (Figure 2(b)). For further characterisation, the iPSCs were seeded on cover slips for immunohistochemical staining (Figures 2(c)-2(f)). Analyses of the two most important pluripotency-associated markers Oct4 (Figure 2(c)) and Nanog (Figure 2(d)) clearly depicted the colocalisation of these markers with the DAPI stained nuclei (Figure 2(e)) of toxic-milk iPSC colonies. Furthermore, the pluripotent status of the toxic-milk iPSC colonies was confirmed by alkaline phosphatase (AP) activity as depicted in Figure $2(\mathrm{~g})$, which is a functional hallmark of reprogrammed pluripotent stem cells. Our findings were further supported by quantitative analyses of the gene expression profile by qRT PCR (Figure 2(i)). The derived toxic-milk iPSC line shows a high expression level of the pluripotent markers Oct4, Nanog, and Sox 2 referred to silent transcriptional activity in the starting murine embryonic fibroblasts. Compared to control embryonic stem cells (ESCs), derived from Oct4-GFP transgenic (OG2) mice, the gene expression of these markers was slightly reduced, but the proportions between the different markers reflected the expression pattern of murine embryonic stem cells. Toxicmilk iPSCs were able to form teratomas when transplanted subcutaneously into NOD/SCID mice (Figures 2(j)-2(l)), and, moreover, the reprogramming transgenes were shown to be silenced in the fully reprogrammed iPSCs (Supplementary Figure 1(A) which is available online at doi: $10.4061 / 2011 / 924782$ ). Karyotype analysis revealed a diploid set of 40 chromosomes (Figure $2(\mathrm{~h})$ ). To summarise, our toxic-milk iPSC line exhibited the most important pluripotent stem cells' characteristics suggesting a well-established pluripotency network and a fully pluripotent status of these reprogrammed cells.

For the hepatic differentiation of toxic-milk iPS cells we used a protocol based on the generation of cell aggregates in embryoid bodies [17, 21]. The embryoid bodies were first cultured in "hanging drops" and then plated in media containing $\alpha$-monothioglycerol supporting endodermal specification, before maturation in hepatocyte culture medium (HCM), which supports differentiation of hepatic precursor cells. At the final stage of this protocol, we obtained cells exhibiting a polygonal morphology, which resembled definitive endoderm-derived hepatic cells (Figure 3(a)). For further analyses, the differentiated cells were transduced with a lentiviral reporter construct expressing enhanced green fluorescent protein (eGFP) under transcriptional control of the Albumin promoter/enhancer cassette [21]. This assay identified the polygonal-shaped differentiated cells as eGFPexpressing hepatic cells (Figure 3(b)) obtained at the final step of the differentiation protocol. However, the total amount of eGFP-positive cells was below 10\%, and, therefore, the putative hepatic cells were purified by fluorescenceactivated cells sorting (FACS) prior to gene expression analyses by quantitative RT-PCR (Figure 3(c)). The toxic-milk iPSC-derived hepatic cells expressed the adult hepatic marker albumin (Alb), the progenitor marker $\alpha$-fetoprotein (Afp), cytokeratin 18 (Ck18), which is a marker distinguishing hepatic cells from cholangiocytic cells, transthyretin (Ttr), and hepatocyte nuclear factor $4 \alpha(\mathrm{Hnf} 4 \alpha)$. Furthermore, expression of the apical conjugate export pump MRP2 (AbcC2) was detectable, which is a hallmark of polarized hepatocytes, exhibiting a (sinusoidal) basolateral and (canalicular) apical membrane domain. Next, we applied $250 \mu \mathrm{M}$ copper sulphate during the last 7 days of hepatic differentiation and evaluated ATP7B-mediated copper transport in toxic-milk iPSC-derived hepatic cells in comparison to hepatic cells from controls ( $\mathrm{C} 3 \mathrm{H}$ mice-derived iPSCs). The number of hepatic cells derived from the control C3H-iPSCs increased 1.8-fold when $250 \mu \mathrm{M}$ copper sulphate was added, due to the toxic effect of copper on nonhepatic cells in the bulk fraction of differentiating cells (Figure 3(d)). Remarkably, hepatic cells derived from the toxic-milk iPSCs were not protected during the copper sulphate challenge, which confirms the ATB7B-deficient phenotype of these cells.

\section{2. iPSC From FAH-Deficient Mice to Study Tyrosinemia} Type 1. As a second murine model of hereditary metabolic liver diseases, we investigated fumarylacetoacetate hydrolase knockout $\left(\mathrm{FAH}^{-/-}\right)$mice [28], which serve as a model for acute tyrosinemia type 1 , resulting in a lethal neonatal liver dysfunction phenotype [34]. We have generated iPSCs from these mice by transduction of $\mathrm{FAH}^{-/-}$-MEFs with retroviral vectors encoding mouse Oct4, Sox2, Klf4, and c-Myc. 9-12 days after initial transduction first iPSC-like colonies were observed, which were subcloned as individual $\mathrm{FAH}^{-/-}$-iPSC lines on day 16 (Figure 4(a)). The expression of endogenous pluripotency markers in these reprogrammed cells was confirmed by immunofluorescence staining against murine Oct4 and Nanog (Figures 4(b) and 4(c)). Fully reprogrammed $\mathrm{FAH}^{-/-}$-iPSCs cells showed effective silencing of reprogramming transgenes (Supplementary Figure 1(B)), retained a normal karyotype (Figure $4(\mathrm{~d})$ ) and activated the endogenous pluripotency network with strong expression of Oct4, Nanog, and Sox2 (Figure 4(e)). Furthermore, 5 weeks after subcutaneous injection of $1 \times 10^{6}$ undifferentiated $\mathrm{FAH}^{-/-}$iPSCs into NOD/SCID mice we could analyse teratomas, which contained various cell types from all three germ layers as depicted in Figures 4(f)-4(g). Next, we applied 


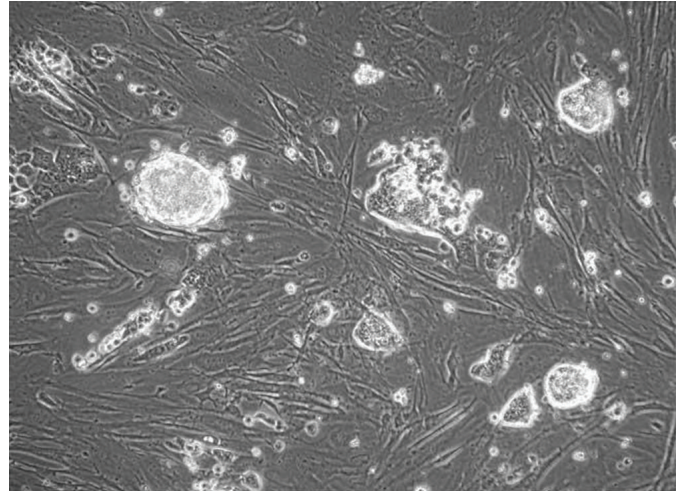

(a)

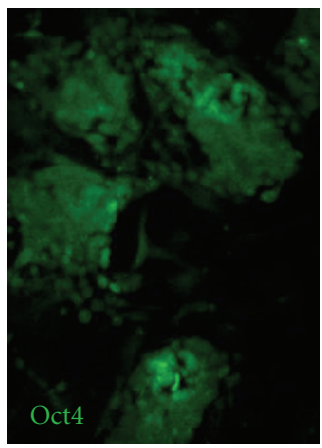

(c)

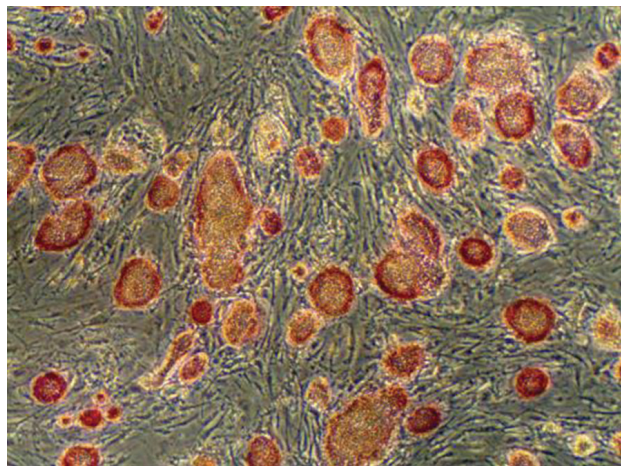

(g)

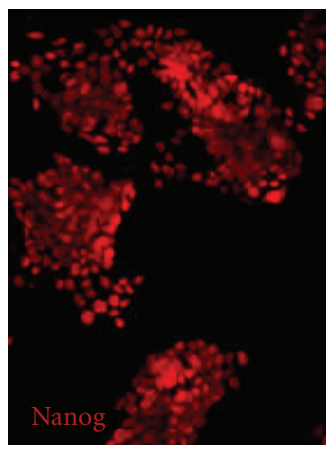

(d)

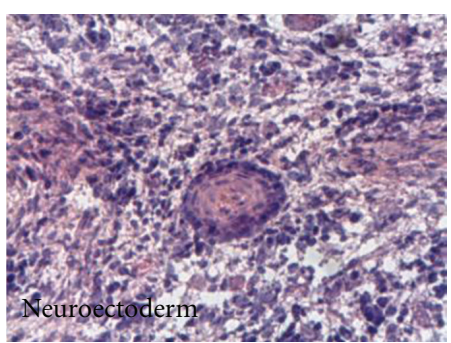

(j)

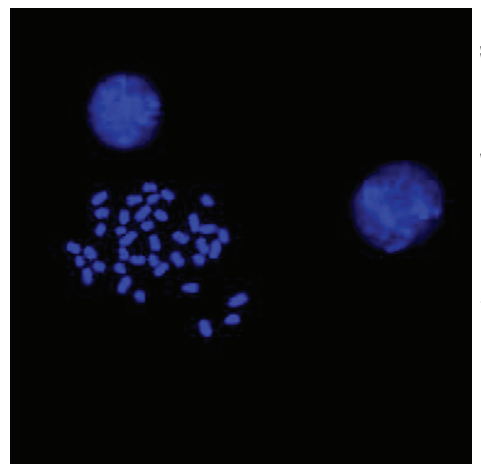

(h)

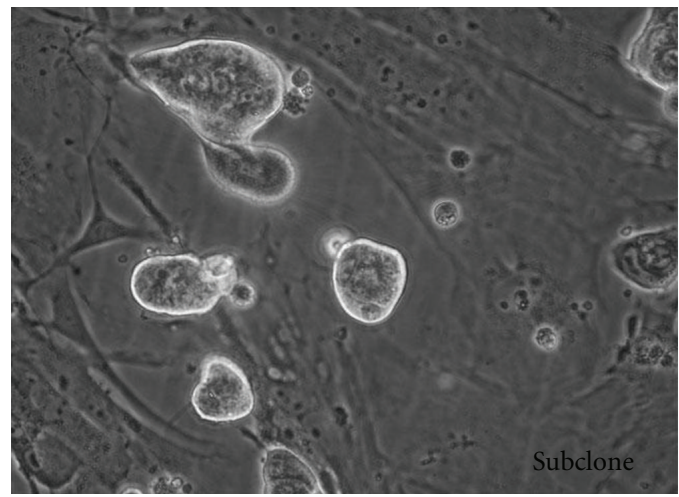

(b)

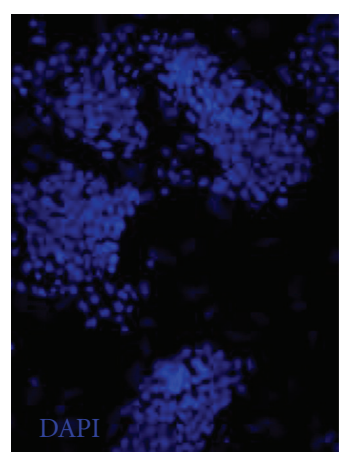

(e)

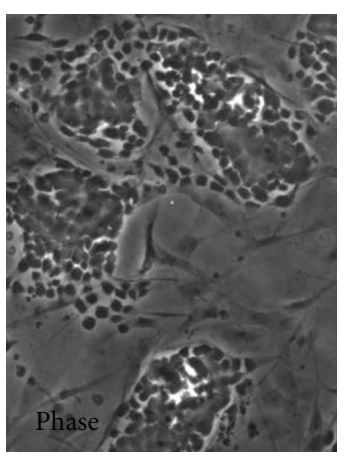

(f)

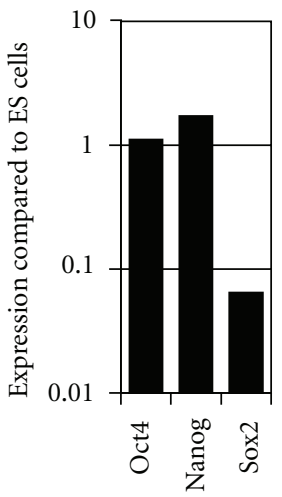

(i)

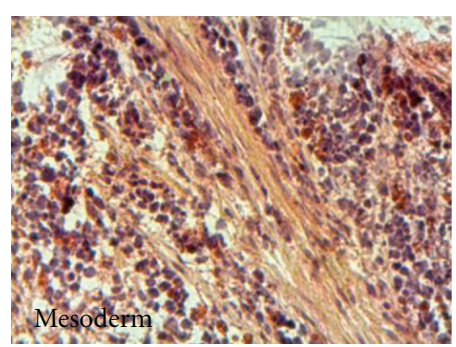

(k)

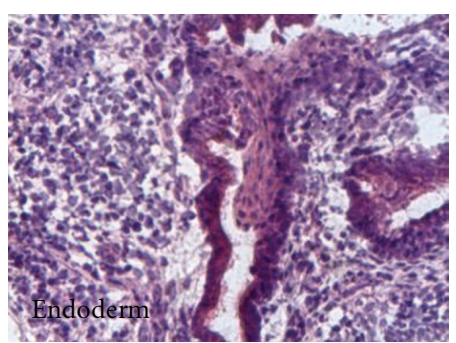

(1)

Figure 2: Generation \& characterization of toxic milk iPS cells. (a) iPSCs generated from fibroblasts isolated from toxic-milk mice using retroviral vectors expressing human OCT4, KLF4, SOX2 and c-MYC. (b) iPSCs were subcloned to obtain better colony morphology. (c)-(f) Subcloned iPSCs stained positive for murine Oct4 and Nanog, whilst DAPI was used to stain the nuclei. (g) Staining for alkaline phosphatase expression of toxic-milk iPSC subclones. (h) Karyotype analysis of DAPI stained metaphase spreads. (i) qRT PCR analysis for endogenous Oct4, Nanog and Sox 2 expression in toxic-milk iPSCs and OG2 ESCs compared to mouse embryonic stem cells. (j)-(l) Teratoma sections depicting formation of neuroectoderm, mesoderm (connective tissue), and endoderm. 


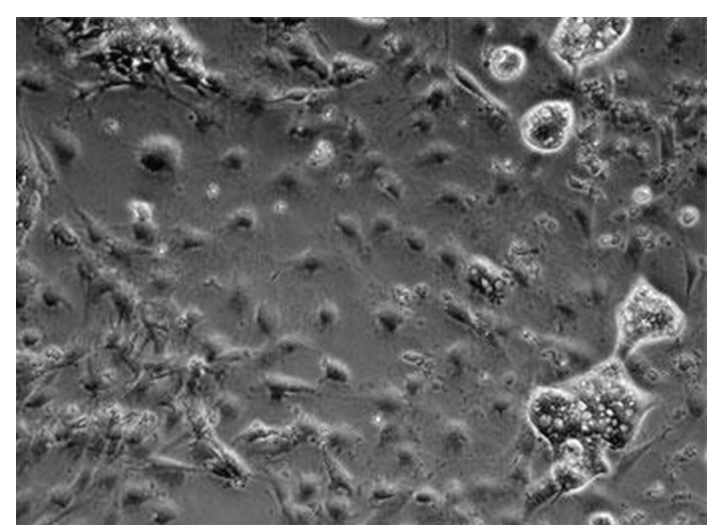

(a)

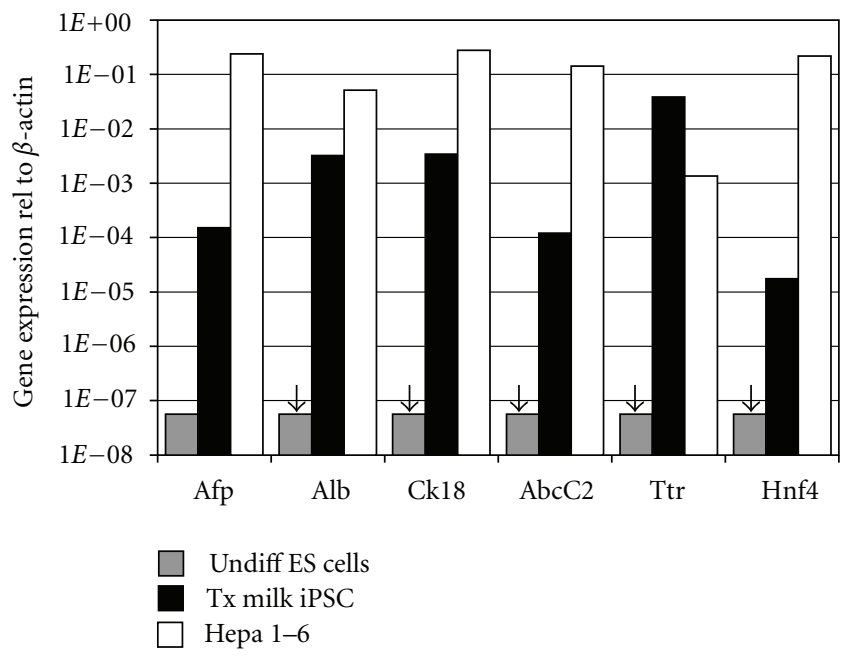

(c)

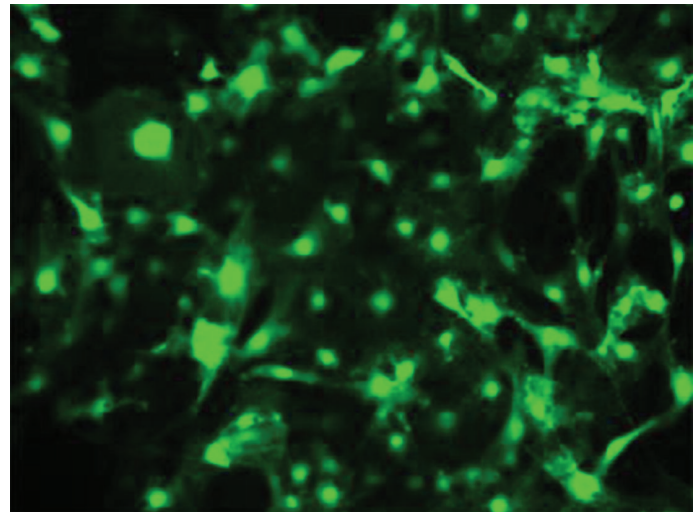

(b)

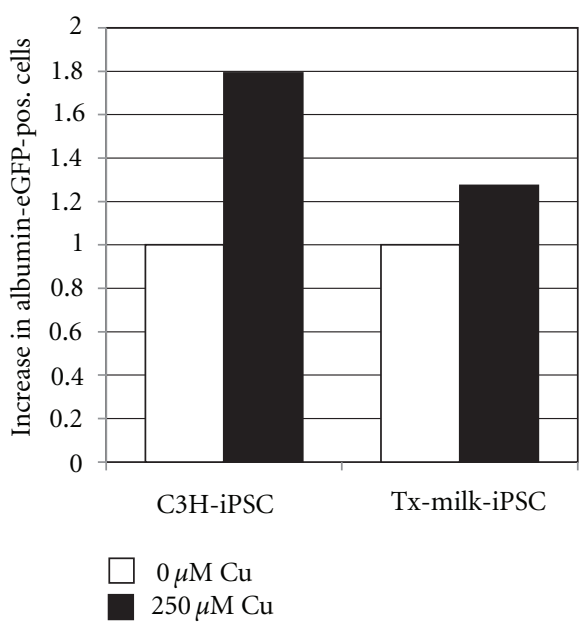

(d)

FIGURE 3: Hepatic differentiation of toxic milk iPS cells. (a, b) Toxic-milk iPS were subjected to hepatic differentiation using hanging drop method and transduced with lentiviral Alb-GFP expression vector. (c) qRT PCR analysis for hepatic marker genes Afp, Alb, Ck18, Abcc2, Ttr, and Hnf4 $\alpha$. Undifferentiated cells served as negative control, in which no hepatic gene expression was determined until cycle 45 ( $\downarrow$ ). (d) During the last seven days of differentiation, the cells were challenged with copper. The toxic-milk mice-derived cells could not export copper, and, therefore, no enrichment of Alb-positive cells was achieved. However, C3H-derived control cells were able to "detoxify" copper after hepatic specifications and, therefore, Alb-eGFP-positive cells were enriched.

the previously described hepatic in vitro differentiation protocol also to the $\mathrm{FAH}^{-1-}$-iPSCs. After differentiation, $\mathrm{FAH}^{-/-}$-iPSCs showed expression of a set of characteristic hepatic markers (Afp, Alb, Ck18, AbcC2, Ttr, Hnf4) as shown in Figure 4(i). The amount of hepatic cells derived from the $\mathrm{FAH}^{-/-}$-iPSCs was estimated by the proportion of eGFP-positive cells (Figures $4(j)-4(\mathrm{k})$ ), at the end of the differentiation period (day $5+9+20$ ), three days after transduction with the lentiviral reporter construct expressing eGFP driven by the Albumin promoter/enhancer [21]. Because neonatal $\mathrm{FAH}^{-/-}$-mice can be rescued from hepatic failure by supplementation with the compound 2-(2-nitro-4trifluoromethylbenzoyl)-1,3 cyclohexanedione (NTBC) we also added this substance during the last 10 days of the in vitro differentiation protocol to a subset of our experiments (Figures 4(l)-4(m)). Fluorescence microscopy at the end of the differentiation protocol revealed that the treatment with $20 \mu \mathrm{g} / \mathrm{mL}$ of NTBC supports the viability of hepatic cells derived from $\mathrm{FAH}^{-1-}$-iPSCs, as we could observe a higher proportion of Alb-eGFP pos cells in the differentiated population of cells receiving NTBC (Figure 4(1)) compared to differentiated cells from untreated cells (Figure $4(\mathrm{j})$ ).

3.3. PiZ Mice-Derived iPSCs for Studying $\alpha 1$-Antitrypsin Deficiency. As a third murine model of a hereditary metabolic liver disease, we investigated PiZ-mice, which express a mutated form of human $\alpha 1$-antitrypsin and acquire a human disease-specific liver phenotype [27, 29]. The PiZ $\alpha 1$-antitrypsin protein corresponds to a point-mutation (E342K) in the human SERPINA1 gene [35] and is termed proteinase inhibitor Z-variant or PiZ, which is prone to polymerization and accumulation in the endoplasmic reticulum of hepatocytes and can lead to liver cirrhosis and hepatocarcinoma [36]. To generate iPSCs from such 


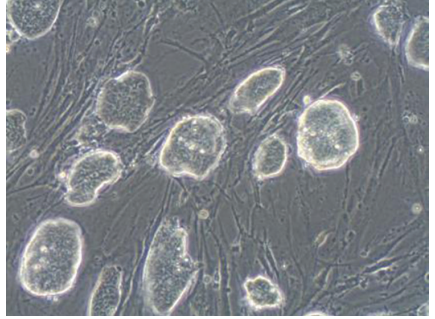

(a)

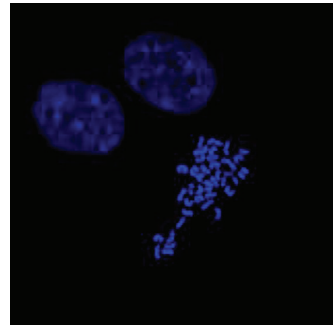

(d)

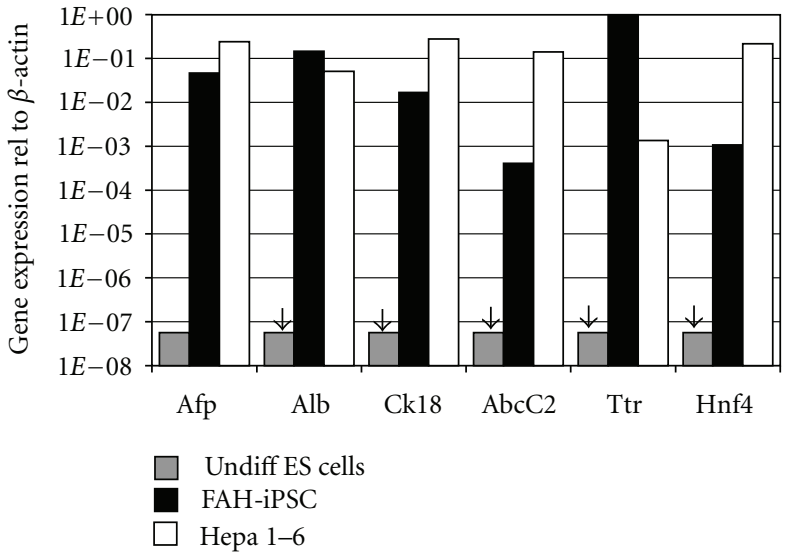

(i)

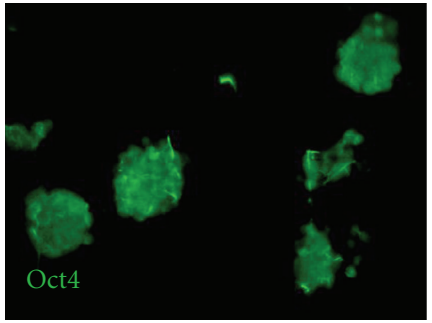

(b)

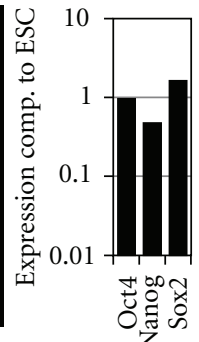

(e)

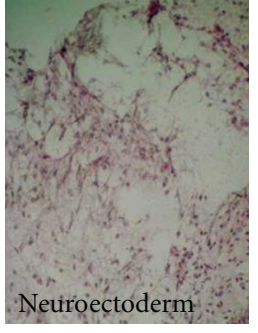

(f)

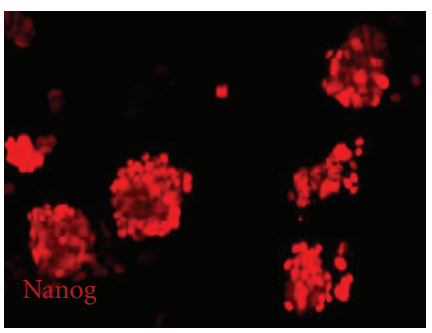

(c)

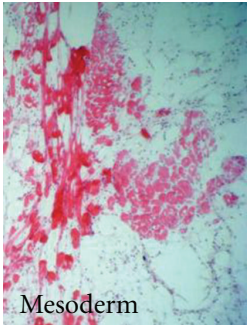

(g)

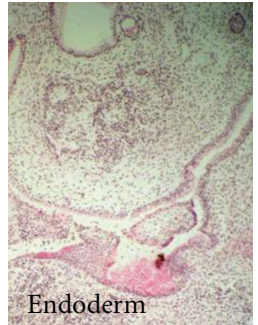

(h)

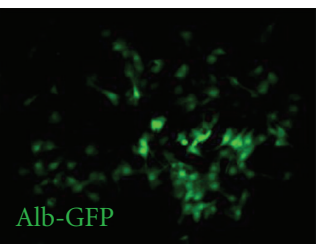

(j)

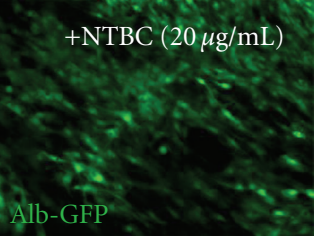

(1)

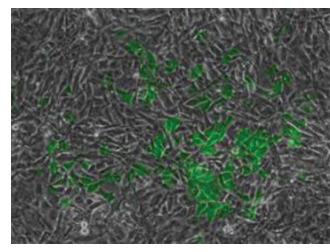

(k)

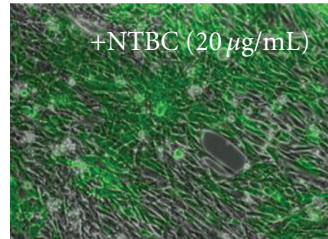

(m)

FIGURE 4: $\mathrm{FAH}^{-/-}$-iPS cells. (a)-(c) iPS generated from fibroblasts isolated from $\mathrm{FAH}^{-/-}$-mice using retroviral vectors expressing human OCT4, KLF4, SOX2, and c-MYC were stained for murine Nanog and Oct4. (d) Karyotype analysis of DAPI stained metaphase spreads. (e) Expression of endogenous Oct4, Nanog, and Sox2 determined by qRT PCR compared to ES cells. (f)-(h) FAH ${ }^{-/-}$-iPSCs were able to form tissues from all three germ layers when transplanted subcutaneously into NOD/SCID mice. (i) qRT PCR analysis for hepatic marker genes Afp, Alb, Ck18, Abcc2, Ttr, and $\mathrm{Hnf} 4 \alpha$. Undifferentiated cells served as negative control, in which no hepatic gene expression was determined until cycle $45(\downarrow)$. (j)-(k) FAH ${ }^{-/-}$-iPSCs differentiated using the hanging drop method and transduced with lentiviral Alb-eGFP expression vector. (l)-(m) $\mathrm{FAH}^{-/-}$-iPSCs differentiated with the same method but with NTBC treatment. The NTBC-treatment rescued the lethal phenotype of hepatic cells, and more Alb-eGFP positive cells were detectable.

PiZ mice, we transduced ear fibroblasts from PiZ-mice with lentiviral vectors encoding human OCT4, SOX2, and KLF4, respectively. 14 days after transduction iPSC-like colonies were picked and subcloned to derive individual PiZ-iPSC lines. These iPSCs depicted all morphological features of murine pluripotent stem cells (Figure 5(a)) with a compact colony shape and a clear shining borderline to the surrounding feeder cells. Moreover, PiZ-iPS cells stained positive for alkaline phosphatase (Figure 5(b)) and possess a diploid karyotype consisting of 40 chromosomes (Figure 5(c)). The characteristic gene expression of endogenous pluripotency markers Oct4, Nanog and Sox 2 was in the same range as control murine embryonic stem cells
(Figure 5(d)), whereas exogenous human OCT4 was silenced when compared to freshly transduced PiZ ear fibroblasts (Supplementary Figure 1(C)). Pluripotency of these PiZiPSCs was further confirmed by teratoma formation after subcutaneous injection into NOD/SCID mice resulting in tumours with various cell types of all three germ layers (Figures $5(\mathrm{e})-5(\mathrm{~g}))$. Finally, we investigated if hepatic derivatives of PiZ-iPSCs express the mutated human $\alpha 1$ antitrypsin variant. To this end, we subjected PiZ-iPSCs to our hepatic differentiation protocol. At day $5+9+3$ after the start of differentiation, we transduced the cells using our lentiviral Alb-eGFP-expressing reporter construct, and we could observe morphologically distinct clusters of 


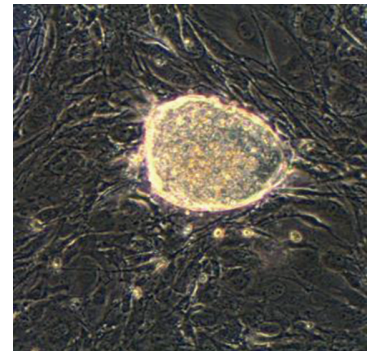

(a)

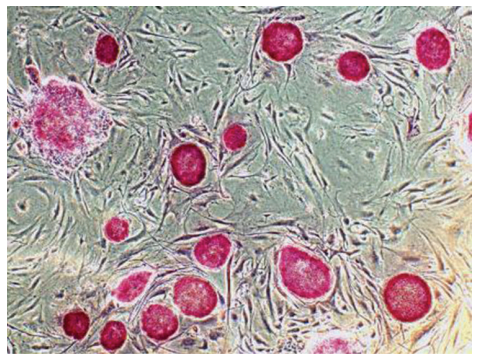

(b)

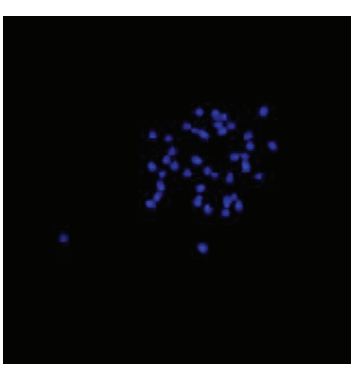

(c)

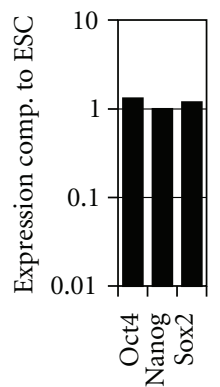

(d)

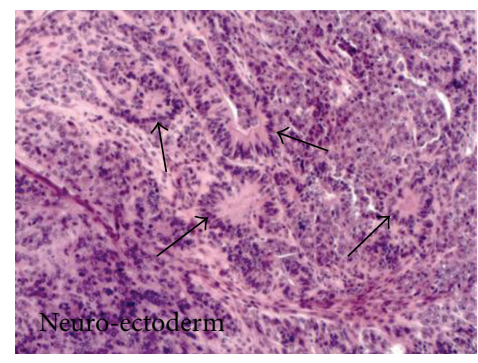

(e)

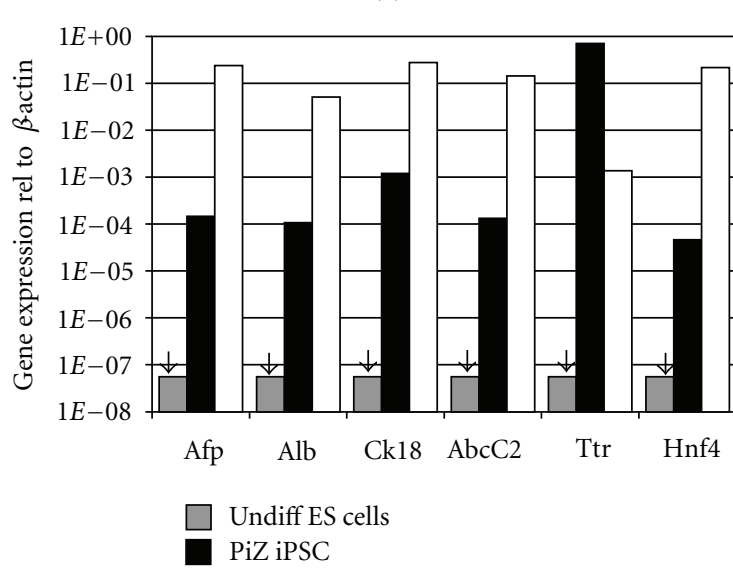

(h)

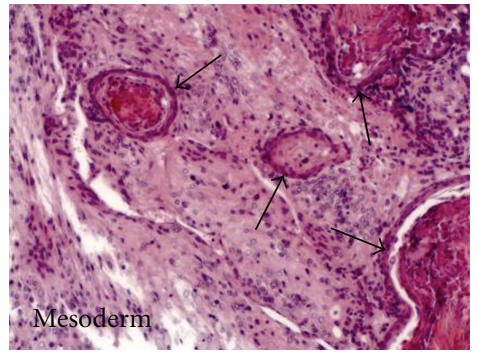

(f)

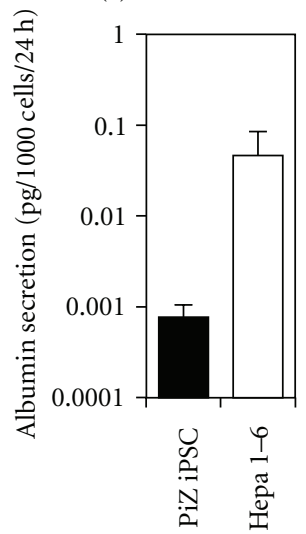

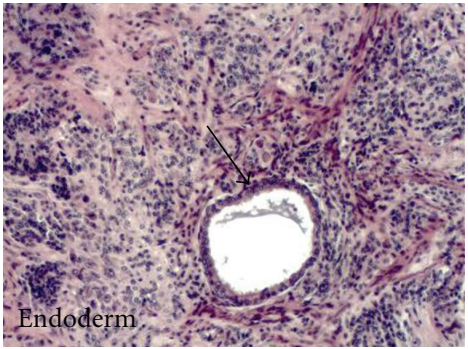

(g)

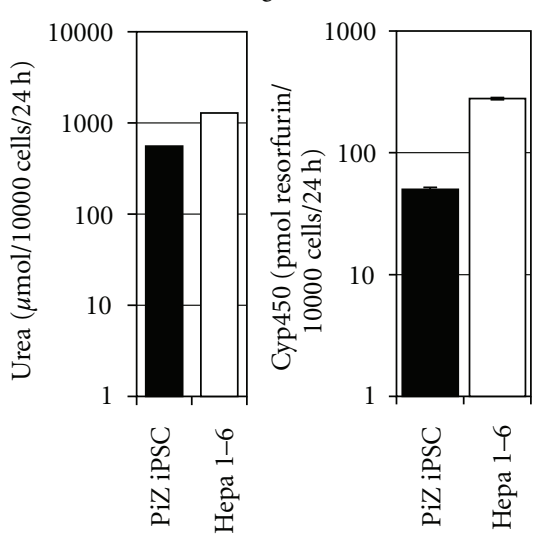

(i)

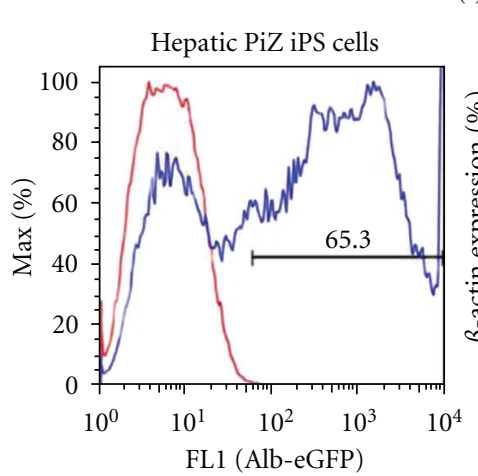

(1)

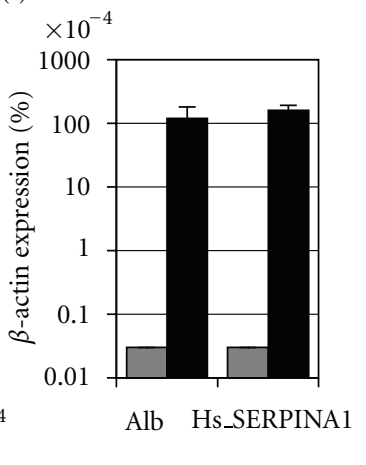

(m)

FIGURE 5: PiZ iPS cells. (a) iPSCs generated from ear fibroblasts isolated from PiZ mice using lentiviral vectors expressing human OCT4, KLF4, and SOX2. (b) Staining for alkaline phosphatase expression of PiZ-iPSCs. (c) Karyotype analysis of DAPI stained metaphase spreads. (d) qRT PCR analysis for endogenous expression of pluripotency markers Oct4, Nanog and Sox2 in PiZ-iPS and OG2 ES. (e)-(g) PiZ iPS were able to form tissues from all three germ layers when transplanted subcutaneously into NOD/SCID mice. (h) qRT PCR analysis for hepatic marker genes Afp, Alb, Ck18, Abcc2, Ttr, and $\mathrm{Hnf} 4 \alpha$. Undifferentiated cells served as negative control, in which no hepatic gene expression was determined until cycle $45(\downarrow)$. (i) Functional analysis of iPSC-derived hepatic cells: albumin secretion detected by ELISA, urea production, and CYP450 activity assay. (j)-(k) Day $5+9+14$ hepatic differentiated PiZ-iPSCs transduced on day $5+9+3$ with a lentiviral Alb-eGFP reporter construct (1) FACS-analysis on day $5+9+14$ of hepatic differentiation for Alb-GFP positive cells. (m) qRT PCR analysis for expression of human SERPINA1 and Albumin on d $5+9+14$ of cytokine-based differentiation, compared to undifferentiated PiZ-iPSCs (grey bars). 
eGFP-positive hepatic cells derived from differentiated PiZiPSCs on day $5+9+14$ (Figures $5(\mathrm{j})-5(\mathrm{k})$ ). Differentiated and transduced cells were also analyzed by flow cytometry for Alb-GFP positive cells on day $5+9+14$ (Figure 5(l)) demonstrating that the majority of cells $(65.3 \%)$ exhibited a hepatic phenotype. When we applied Taqman-based qRT PCR analysis to these hepatic PiZ-iPSC-derivatives, we were able to confirm the hepatic phenotype by showing expression of a set of characteristic hepatic markers, such as Afp, Alb, Ck18, AbcC2, Ttr, Hnf4 (Figure 5(h)), and, more importantly, we detected expression of the disease-causing PiZ variant of the human SERPINA1 transgene, which was as strong as albumin expression (Figure 5(m)). Functionality of differentiated PiZ iPSCs was characterized by measuring albumin secretion by ELISA, urea production, and CYP450 activity (Figure 5(i)).

Combining two recent breakthroughs in stem-cell biology, the generation of patient-derived pluripotent stem cells [37] and the generation of hepatic cells from uncommitted pluripotent stem cells $[16,18-20,25]$, new therapeutic approaches for various metabolic liver diseases may emerge. With respect to metabolic liver diseases, two recent publications support the feasibility of generating such diseasespecific iPS cells from murine [38] and human individuals [39]. Those cells offer a unique opportunity for studies of the pathophysiology of the respective disease on a cellular level. To this end, we investigated whether hepatic progenitors depicting the pathophysiological hallmarks of the respective disease can be generated from iPSCs derived from murine models of the copper storage disorders Wilson's disease [26], of acute tyrosinemia type I [28], and of $\alpha 1$-antitrypsin deficiency [29]. All three murine disease models cover the relevant characteristics of the hepatic disease phenotypes in patients and were well-studied animal models.

Although recent publications suggest alternative approaches for iPSC generation such as use of nonintegrating viral vectors [40-43], protein transduction [44, 45], plasmid transfection [46], or stabilized mRNA application [47], we chose the well-established gamma-retroviral vector system $[7,31]$ for delivery of the reprogramming factors to MEFs from toxic-milk mice and $\mathrm{FAH}^{-/-}$-mice and a recently improved lentiviral delivery system for iPSC generation from PiZ-mouse fibroblasts [48]. In the light of recent publications discriminating between partially and fully reprogrammed iPSCs and differences in the epigenetic memory in iPSCs [49-51], we assume that the robust viral delivery method is the most stable reprogramming system. This conclusion is supported by the fact that fully iPSC-derived mice were so far only generated using iPSCs derived by these viral techniques for complementation of nondeveloping tetraploid embryos $[49,52-54]$. The molecular and functional data from our experiments provides strong evidence that our iPSC from the various disease models are fully reprogrammed as we observed a stable ES-like morphology for multiple passages, strong expression of pluripotency markers and, most importantly, unimpaired differentiation capabilities into hepatic cells, applying in vitro differentiation protocols.

Even if the embryoid body-based hepatic differentiation protocol $[17,21]$ does not use the extrinsic supplementation of instructive cytokines as Activin A or BMP4 for induction of endodermal differentiation, we robustly obtained a proportion of around $10 \%$ of the cells, which acquired a hepatic phenotype. Furthermore, these cells functionally correlated to the respective diseases, such as sensitivity to excess copper administration in toxic-milk hepatic cells or response to NTBC treatment in $\mathrm{FAH}^{-/-}$-hepatic cells. When we analyzed the $\alpha 1$-antritrypsin related iPSCs from PiZ mice, we chose a recently established cytokine-based differentiation protocol, which is based on a monolayer cell culture in serum-free media conditions [16]. Preliminary results suggested that the hepatic cells obtained with this protocol are more mature, but the overall reproducibility of this protocol needs further attention. Most probably, the optimal cytokine application schedule is strongly dependent on cell proliferation and density as well as on other factors during the time course of differentiation, and, therefore, the robustness of this protocol is not easy to achieve. Nevertheless, we chose this protocol for the hepatic differentiation of PiZ-iPSCs, because we aim to further elaborate on the $\alpha 1$-antitrypsin-defiency with patient-derived iPSC in the future, which only is possible with cytokine-based protocols acting on monolayer human iPSC cultures.

\section{Conclusions}

Here, we successfully generated iPSC from three highly relevant murine metabolic liver disease models, and we established in vitro differentiation into disease-specific hepatic cells, which exhibit the pathophysiological phenotype of the clinical condition. Such cells will allow future studies on new drug targets or gene repair strategies for the respective metabolic liver disorder.

\section{Acknowledgments}

The authors are very grateful to Holm Zaehres and Axel Schambach for generation of and support with viral constructs (pMX retroviruses for the generation of toxic-milk iPSC and FAH iPSC (H.Z.), lentiviral vectors (A.S.) for the generation of PiZ iPSCs). Furthermore, they thank Martina Radstaak for excellent technical assistance. Parts of this work were funded by the Federal Ministry of Education and Research (Grants nos. 01GN0812, 01GM0854) and by the German Research foundation (DFG EXC 62/1).

\section{References}

[1] I. J. Fox, J. R. Chowdhury, S. S. Kaufman et al., "Treatment of the Crigler-Najjar syndrome type I with hepatocyte transplantation," The New England Journal of Medicine, vol. 338, no. 20, pp. 1422-1426, 1998.

[2] R. A. Fisher and S. C. Strom, "Human hepatocyte transplantation: worldwide results," Transplantation, vol. 82, no. 4, pp. 441-449, 2006.

[3] A. Schneider, M. Attaran, P. N. Meier et al., "Hepatocyte transplantation in an acute liver failure due to mushroom poisoning," Transplantation, vol. 82, no. 8, pp. 1115-1116, 2006. 
[4] A. Dhawan, R. R. Mitry, and R. D. Hughes, "Hepatocyte transplantation for liver-based metabolic disorders," Journal of Inherited Metabolic Disease, vol. 29, no. 2-3, pp. 431-435, 2006.

[5] M. Najimi and E. Sokal, "Liver cell transplantation," Minerva Pediatrica, vol. 57, no. 5, pp. 243-257, 2005.

[6] J. Meyburg, A. M. Das, F. Hoerster et al., "One liver for four children: first clinical series of liver cell transplantation for severe neonatal urea cycle defects," Transplantation, vol. 87, no. 5, pp. 636-641, 2009.

[7] K. Takahashi and S. Yamanaka, "Induction of pluripotent stem cells from mouse embryonic and adult fibroblast cultures by defined factors," Cell, vol. 126, no. 4, pp. 663-676, 2006.

[8] K. Okita, T. Ichisaka, and S. Yamanaka, "Generation of germline-competent induced pluripotent stem cells," Nature, vol. 448, no. 7151, pp. 313-317, 2007.

[9] A. Meissner, M. Wernig, and R. Jaenisch, "Direct reprogramming of genetically unmodified fibroblasts into pluripotent stem cells," Nature Biotechnology, vol. 25, no. 10, pp. 11771181, 2007.

[10] N. Maherali, R. Sridharan, W. Xie et al., "Directly Reprogrammed fibroblasts show global epigenetic remodeling and widespread tissue contribution," Cell Stem Cell, vol. 1, no. 1, pp. 55-70, 2007.

[11] K. Takahashi, K. Tanabe, M. Ohnuki et al., "Induction of Pluripotent Stem Cells from Adult Human Fibroblasts by Defined Factors," Cell, vol. 131, no. 5, pp. 861-872, 2007.

[12] J. Yu, M. A. Vodyanik, K. Smuga-Otto et al., "Induced pluripotent stem cell lines derived from human somatic cells," Science, vol. 318, no. 5858, pp. 1917-1920, 2007.

[13] I. H. Park, R. Zhao, J. A. West et al., "Reprogramming of human somatic cells to pluripotency with defined factors," Nature, vol. 451, no. 7175, pp. 141-146, 2008.

[14] J. Hanna, M. Wernig, S. Markoulaki et al., "Treatment of sickle cell anemia mouse model with iPS cells generated from autologous skin," Science, vol. 318, no. 5858, pp. 1920-1923, 2007.

[15] A. Raya, I. Rodríguez-Piz, G. Guenechea et al., "Diseasecorrected haematopoietic progenitors from Fanconi anaemia induced pluripotent stem cells," Nature, vol. 460, no. 7251, pp. 53-59, 2009.

[16] K. Loya, R. Eggenschwiler, K. Ko et al., "Hepatic differentiation of pluripotent stem cells," Biological Chemistry, vol. 390, no. 10, pp. 1047-1055, 2009.

[17] G. Kania, P. Blyszczuk, A. Jochheim, M. Ott, and A. M. Wobus, "Generation of glycogen- and albumin-producing hepatocytelike cells from embryonic stem cells," Biological Chemistry, vol. 385, no. 10, pp. 943-953, 2004.

[18] D. C. Hay, D. Zhao, A. Ross, R. Mandalam, J. Lebkowski, and W. Cui, "Direct differentiation of human embryonic stem cells to hepatocyte-like cells exhibiting functional activities," Cloning and Stem Cells, vol. 9, no. 1, pp. 51-62, 2007.

[19] J. Cai, Y. Zhao, Y. Liu et al., "Directed differentiation of human embryonic stem cells into functional hepatic cells," Hepatology, vol. 45, no. 5, pp. 1229-1239, 2007.

[20] T. Cantz, M. Bleidißel, M. Stehling, and H. R. Schöler, "In vitro differentiation of reprogrammed murine somatic cells into hepatic precursor cells," Biological Chemistry, vol. 389, no. 7, pp. 889-896, 2008.

[21] A. D. Sharma, T. Cantz, A. Vogel et al., "Murine embryonic stem cell-derived hepatic progenitor cells engraft in recipient livers with limited capacity of liver tissue formation," Cell Transplantation, vol. 17, no. 3, pp. 313-323, 2008.

[22] J. Heo, V. M. Factor, T. Uren et al., "Hepatic precursors derived from murine embryonic stem cells contribute to regeneration of injured liver," Hepatology, vol. 44, no. 6, pp. 1478-1486, 2006.

[23] V. Gouon-Evans, L. Boussemart, P. Gadue et al., "BMP-4 is required for hepatic specification of mouse embryonic stem cell-derived definitive endoderm," Nature Biotechnology, vol. 24, no. 11, pp. 1402-1411, 2006.

[24] M. Ek, T. Söderdahl, B. Küppers-Munther et al., "Expression of drug metabolizing enzymes in hepatocyte-like cells derived from human embryonic stem cells," Biochemical Pharmacology, vol. 74, no. 3, pp. 496-503, 2007.

[25] T. Touboul, N. R. F. Hannan, S. Corbineau et al., "Generation of functional hepatocytes from human embryonic stem cells under chemically defined conditions that recapitulate liver development," Hepatology, vol. 51, no. 5, pp. 1754-1765, 2010.

[26] V. Coronado, M. Nanji, and D. W. Cox, "The Jackson toxic milk mouse as a model for copper loading," Mammalian Genome, vol. 12, no. 10, pp. 793-795, 2001.

[27] C. Kriegeskotte, T. Cantz, J. Haberland et al., "Laser secondary neutral mass spectrometry for copper detection in micro-scale biopsies," Journal of Mass Spectrometry, vol. 44, no. 10, pp. 1417-1422, 2009.

[28] M. Grompe, "Principles of therapeutic liver repopulation," Journal of Inherited Metabolic Disease, vol. 29, no. 2-3, pp. 421425, 2006.

[29] J. A. Carlson, B. Barton Rogers, R. N. Sifers et al., "Accumulation of PiZ $\alpha 1$-antitrypsin causes liver damage in transgenic mice," Journal of Clinical Investigation, vol. 83, no. 4, pp. 11831190, 1989.

[30] P. E. Szabó, K. Hübner, H. Schöler, and J. R. Mann, “Allelespecific expression of imprinted genes in mouse migratory primordial germ cells," Mechanisms of Development, vol. 115, no. 1-2, pp. 157-160, 2002.

[31] H. Zaehres, G. Kögler, M. J. Arauzo-Bravo et al., "Induction of pluripotency in human cord blood unrestricted somatic stem cells," Experimental Hematology, vol. 38, no. 9, pp. 809-818, 2010.

[32] D. R. Wybenga, J. Di Giorgio, and V. J. Pileggi, "Manual and automated methods for urea nitrogen measurement in whole serum," Clinical Chemistry, vol. 17, no. 9, pp. 891-895, 1971.

[33] J. F. Payne and W. R. Penrose, "Induction of aryl hydrocarbon (Benzo[a]pyrene) hydroxylase in fish by petroleum," Bulletin of Environmental Contamination and Toxicology, vol. 14, no. 1, pp. 112-116, 1975.

[34] M. Grompe, "The pathophysiology and treatment of hereditary tyrosinemia type 1," Seminars in Liver Disease, vol. 21, no. 4, pp. 563-571, 2001.

[35] E. Savransky, P. Hytiroglou, N. Harpaz, S. N. Thung, and E. M. Johnson, "Correcting the PiZ defect in the $\alpha 1$-antitrypsin gene of human cells by targeted homologous recombination," Laboratory Investigation, vol. 70, no. 5, pp. 676-683, 1994.

[36] N. O. Berg and S. Eriksson, "Liver disease in adults with alpha-1 -antitrypsin deficiency," The New England Journal of Medicine, vol. 287, no. 25, pp. 1264-1267, 1972.

[37] I. H. Park, N. Arora, H. Huo et al., "Disease-Specific Induced Pluripotent Stem Cells," Cell, vol. 134, no. 5, pp. 877-886, 2008.

[38] S. Espejel, G. R. Roll, K. J. McLaughlin et al., "Induced pluripotent stem cell - derived hepatocytes have the functional and proliferative capabi lities needed for liver regeneration in mice," Journal of Clinical Investigation, vol. 120, no. 9, pp. 3120-3126, 2010.

[39] S. T. Rashid, S. Corbineau, N. Hannan et al., "Modeling inherited metabolic disorders of the liver using human induced 
pluripotent stem cells," Journal of Clinical Investigation, vol. 120, no. 9, pp. 3127-3136, 2010.

[40] M. Stadtfeld, M. Nagaya, J. Utikal, G. Weir, and K. Hochedlinger, "Induced pluripotent stem cells generated without viral integration," Science, vol. 322, no. 5903, pp. 945949, 2008.

[41] N. Fusaki, H. Ban, A. Nishiyama, K. Saeki, and M. Hasegawa, "Efficient induction of transgene-free human pluripotent stem cells using a vector based on Sendai virus, an RNA virus that does not integrate into the host genome," Proceedings of the Japan Academy Series B, vol. 85, no. 8, pp. 348-362, 2009.

[42] J. Yu, K. Hu, K. Smuga-Otto et al., "Human induced pluripotent stem cells free of vector and transgene sequences," Science, vol. 324, no. 5928, pp. 797-801, 2009.

[43] F. Jia, K. D. Wilson, N. Sun et al., "A nonviral minicircle vector for deriving human iPS cells," Nature Methods, vol. 7, no. 3, pp. 197-199, 2010.

[44] H. Zhou, S. Wu, J. Y. Joo et al., "Generation of induced pluripotent stem cells using recombinant proteins," Cell Stem Cell, vol. 4, no. 5, pp. 381-384, 2009.

[45] D. Kim, C. H. Kim, J. I. Moon et al., "Generation of human induced pluripotent stem cells by direct delivery of reprogramming proteins," Cell Stem Cell, vol. 4, no. 6, pp. 472476, 2009.

[46] K. Okita, M. Nakagawa, H. Hyenjong, T. Ichisaka, and S. Yamanaka, "Generation of mouse induced pluripotent stem cells without viral vectors," Science, vol. 322, no. 5903, pp. 949953, 2008.

[47] L. Warren, P. D. Manos, T. Ahfeldt et al., "Highly efficient reprogramming to pluripotency and directed differentiation of human cells with synthetic modified mRNA," Cell Stem Cell, vol. 7, no. 5, pp. 618-630, 2010.

[48] E. Warlich, J. Kuehle, T. Cantz et al., "Lentiviral vector design and imaging approaches to visualize the early stages of cellular reprogramming," Molecular Therapy, vol. 19, no. 4, pp. 782789, 2011.

[49] M. Stadtfeld, E. Apostolou, H. Akutsu et al., "Aberrant silencing of imprinted genes on chromosome 12qF1 in mouse induced pluripotent stem cells," Nature, vol. 465, no. 7295, pp. 175-181, 2010.

[50] J. M. Polo, S. Liu, M. E. Figueroa et al., "Cell type of origin influences the molecular and functional properties of mouse induced pluripotent stem cells," Nature Biotechnology, vol. 28, no. 8, pp. 848-855, 2010.

[51] K. Kim, A. Doi, B. Wen et al., "Epigenetic memory in induced pluripotent stem cells," Nature, vol. 467, no. 7313, pp. 285290, 2010.

[52] M. J. Boland, J. L. Hazen, K. L. Nazor et al., "Adult mice generated from induced pluripotent stem cells," Nature, vol. 461, no. 7260, pp. 91-94, 2009.

[53] L. Kang, J. Wang, Y. Zhang, Z. Kou, and S. Gao, "iPS cells can support full-term development of tetraploid blastocystcomplemented embryos," Cell Stem Cell, vol. 5, no. 2, pp. 135138, 2009.

[54] X. Y. Zhao, W. Li, Z. Lv et al., "IPS cells produce viable mice through tetraploid complementation," Nature, vol. 461, no. 7260, pp. 86-90, 2009. 

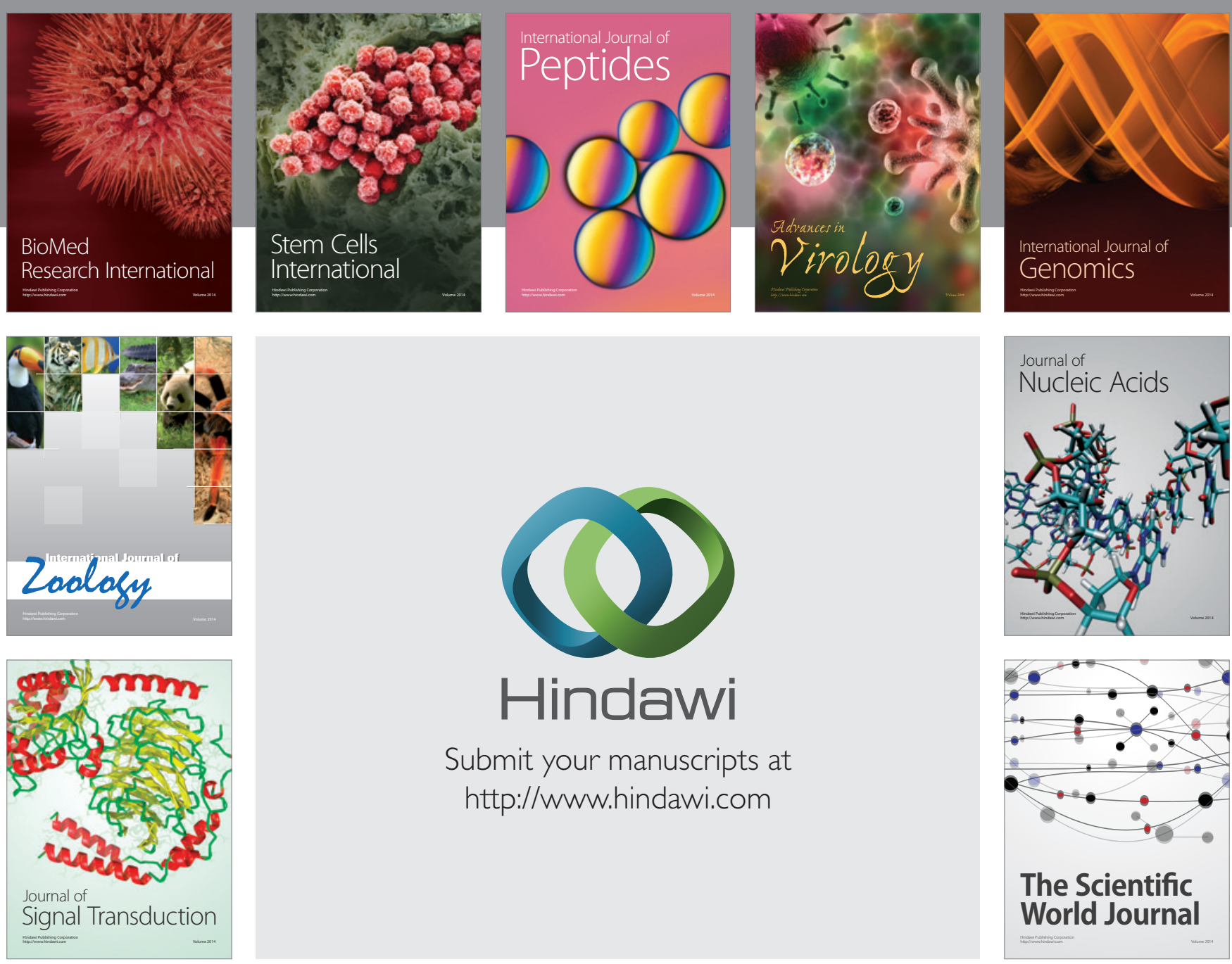

Submit your manuscripts at

http://www.hindawi.com
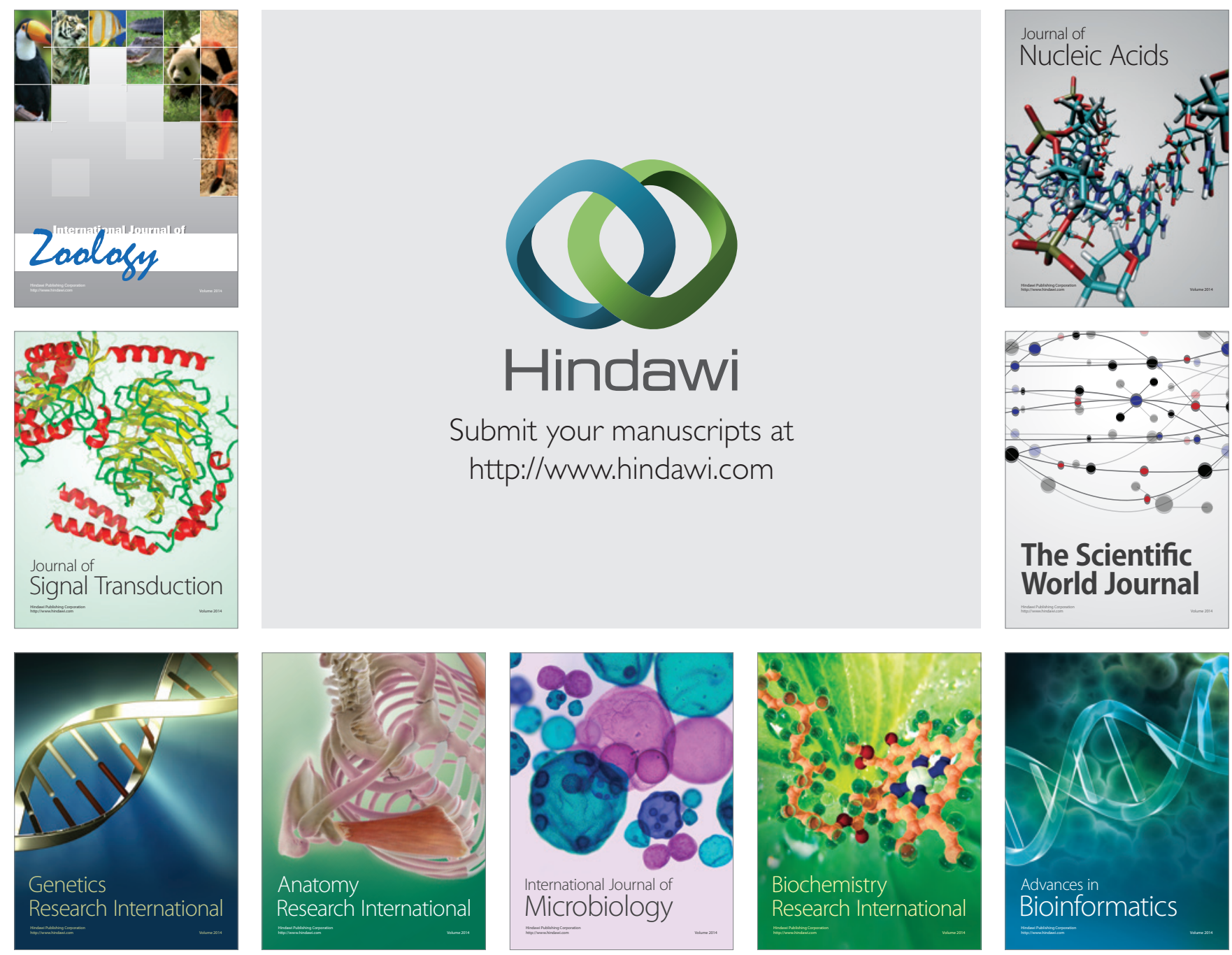

The Scientific World Journal
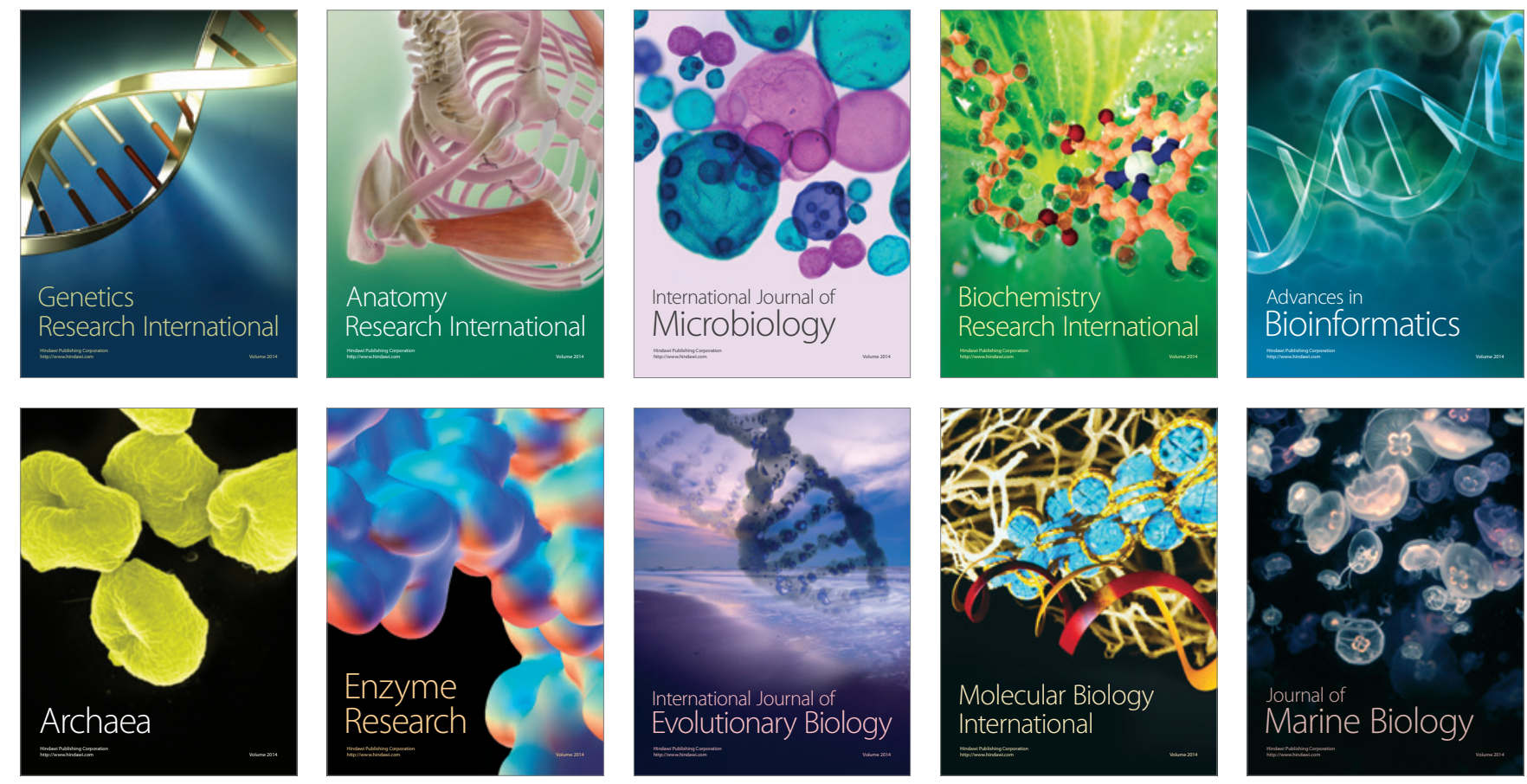